Article

\title{
Evaluating the Heavy Metal Risk in Spinacia oleracea L. and Its Surrounding Soil with Varied Biochar Levels: A Pot Experiment
}

\author{
Gang Xiang ${ }^{1}$, Xianliang $\mathrm{Wu}^{2}\left(\mathbb{D}\right.$ and Shengxing Long ${ }^{1, *}$ \\ 1 School of Geography and Environmental Science, Guizhou Normal University, Guiyang 550025, China; \\ xianggang76@163.com \\ 2 Guizhou Institute of Biology, Guiyang 550009, China; wuxianliang1995@163.com \\ * Correspondence: longshengxing@163.com; Tel.: +86-135-9503-4820
}

check for

updates

Citation: Xiang, G.; Wu, X.; Long, S. Evaluating the Heavy Metal Risk in Spinacia oleracea L. and Its Surrounding Soil with Varied Biochar Levels: A Pot Experiment. Sustainability 2021, 13, 10843. https://doi.org/10.3390/ su131910843

Academic Editors: Zygmunt

Mariusz Gusiatin and Franco Ajmone Marsan

Received: 6 July 2021

Accepted: 23 September 2021

Published: 29 September 2021

Publisher's Note: MDPI stays neutral with regard to jurisdictional claims in published maps and institutional affiliations.

Copyright: (c) 2021 by the authors. Licensee MDPI, Basel, Switzerland. This article is an open access article distributed under the terms and conditions of the Creative Commons Attribution (CC BY) license (https:// creativecommons.org/licenses/by/ $4.0 /)$.

\begin{abstract}
Spinacia oleracea L., as the most widely cultivated green leafy vegetable in China, can threaten human health in cases of its excessive heavy metal content, especially in mining areas of karst landforms. Therefore, the present study mainly investigates whether biochar is useful for remediating heavy metal pollution in soil and S. oleracea and the degree of this improvement in karst areas. The effects of heavy metal exposure on the health of children and adults in S. oleracea and rhizosphere lime soil with six biochar levels are evaluated by a health risk assessment, namely, $4000 \mathrm{~g}$ of lime soil (C-0), $160 \mathrm{~g}$ of biochar $+3840 \mathrm{~g}$ of lime soil (C-160), $240 \mathrm{~g}$ of biochar $+3760 \mathrm{~g}$ of lime soil (C-240), $320 \mathrm{~g}$ of biochar $+3680 \mathrm{~g}$ of lime soil (C-320), $400 \mathrm{~g}$ of biochar $+3600 \mathrm{~g}$ of lime soil (C-400) and $800 \mathrm{~g}$ of biochar $+3200 \mathrm{~g}$ of lime soil (C-800). The results show that the $\mathrm{pH}$ values of the lime soil were positively correlated with $\mathrm{Pb}, \mathrm{P}$ and $\mathrm{K}$ contents and negatively correlated with $\mathrm{As}, \mathrm{Cr}, \mathrm{Hg}, \mathrm{Cd}$ and $\mathrm{N}$ contents in S. oleracea. The assessments of the potential ecological risk index show that the soil samples for the C-0 and C-160 levels pose moderate ecological hazards, while the soil samples for the C-320, C-800, C-400 and C-240 levels constitute mild ecological hazards. The single noncarcinogenic risks, total noncarcinogenic risk indexes, single carcinogenic risks and total carcinogenic risks values indicate that exposure to heavy metals in lime soil and S. oleracea poses a serious threat to human health. It also presents an unacceptable cancer risk and children are more threatened than adults. Our results suggest that heavy metal pollution of $S$. oleracea and its rhizosphere lime soil in karst areas still poses a threat to human health after adding biochar, and the relevant local departments need to implement more active measures to solve the excessive heavy metal contents in the local soil and vegetables of this karst regions.
\end{abstract}

Keywords: heavy metals; biochar; Spinacia oleracea L.; potential ecological risk index; health risk assessment

\section{Introduction}

The soils that are used for planting vegetables in China are faced with soil acidification, secondary salinization, nonpoint source pollution and heavy metal pollution [1]. Heavy metals cannot be degraded in the environment and easily accumulate along the food chain, they thus ultimately endanger human health [2,3]. With improved living standards, humans have higher requirements for food safety and the green production of agricultural products. However, at present, the problem of heavy metal pollution in farmland soil is becoming increasingly prominent [4]. The migration of soil heavy metals through the food chain is an important source of human heavy metal exposure [5]. In particular, vegetables provide an indispensable source of food in the daily lives of humans, and heavy metals accumulate in the human body after the vegetables they pollute are consumed. Therefore, it is urgent to remove heavy metal pollution in vegetable planting soils to ensure food safety.

Karst landforms are unsuitable for agricultural development due to their rugged surfaces, the small size of their cultivated land areas, thin soil layers and infertile soils [6]. Spinacia oleracea L., a common vegetable in Guizhou Province, southwest China, is highly 
adaptable to various soil types and maintains water and fertility [7]. However, several studies have demonstrated that stem and leaf vegetables, including $S$. oleracea have strong abilities to accumulate heavy metals in soil [8,9]. Ru et al. [10] studied the characteristics and control measures of the absorption and accumulation of the heavy metals $\mathrm{Cu}, \mathrm{Zn}$, $\mathrm{Pb}$ and $\mathrm{Cd}$ in S. oleracea. They suggest that the contents of $\mathrm{Cu}, \mathrm{Zn}, \mathrm{Pb}$ and $\mathrm{Cd}$ increased significantly in S. oleracea with increases in the soil contents. With the growth of $S$ oleracea, the trend of increasing heavy metal contents in soil becomes significant. With the addition of heavy metals to soil, only a small portion of the heavy metals in the soil are able to be absorbed by $\mathrm{S}$. oleracea roots, with most $\mathrm{Cu}$ and $\mathrm{Pb}$ accumulating in the roots after their absorption by S. oleracea. Sun et al. [11] studied the accumulations of heavy metals in vegetables and greenhouse soils in Hebei Province. They show that S. oleracea and scallion and garlic seedlings had relatively large enrichment coefficients for five heavy metals. The average bioaccumulation factor for different vegetable categories were ranked in the order of leaf vegetables $>$ root vegetables $>$ bulbous vegetables $>$ fruit vegetables and for different heavy metals, were ranked in the order of $\mathrm{Cd}>\mathrm{Ni}>\mathrm{Cr}>\mathrm{As}>\mathrm{Pb}$. Zubair et al. [12] investigated the concentrations of two heavy metals, $\mathrm{Hg}$ and As, in Spinacia oleracea $\mathrm{L}$. and rhizosphere soil. They suggest that $S$. oleracea is a good accumulator of heavy metals and has shown significant levels of both As and $\mathrm{Hg}$ accumulations. Their concentrations in plants increased with increasing soil concentrations. The abovementioned studies have shown that $S$. oleracea has a strong enrichment ability for heavy metals in soil. Unfortunately, the heavy metal distribution in the karst area in Guizhou Province is anomalous, and its geological background values are higher than those in the other provinces of China [13]. Therefore, especially for areas with higher background values of heavy metals, it is necessary to find low-cost and effective methods to reduce their accumulation through S. oleracea and its rhizosphere soil, thereby decreasing the level of harm to humans.

Biochar is a high-quality energy and soil conditioner, reducing agent, slow-release carrier of fertilizer and is a carbon dioxide storage agent [14]. It has been widely used in carbon fixation and emissions reduction, water purification, heavy metal adsorption and soil improvement [15], especially for heavy metal remediation in soils [16]. Dhiman et al. [17] reported the use of a polyacrylamide superabsorbent polymer hydrogel and of its mixture with pyrolyzed plantain peel biochar for use as a soil amendment to reduce heavy metal uptake by wastewater-irrigated S. oleracea. Malandrino et al. [18] evaluated the effectiveness of vermiculite treatments to reduce the availability of pollutants in two plants, Lactuca sativa and S. oleracea, in pot experiments. They suggest that the addition of vermiculite significantly reduced the uptake of metal pollutants by plants, which confirmed the possibility of using this clay in amendment treatments of metal-contaminated soils. Tan et al. [19] explored the effects of municipal sludge composting on S. oleracea growth and the soil environment. The application of sludge compost had a significant effect on the heavy metal contents in S. oleracea and significantly increased the nutrient and organic matter contents in its rhizosphere soils. There was a significant correlation between the amount of sludge compost and the heavy metal contents in sludge. However, biochar, as a low-cost and green material, is rarely reported with respect to remediating heavy metals in common edible vegetables and the rhizosphere soils in karst areas. Therefore, the objective of the present study is to (1) evaluate the degree of heavy metal pollution (e.g., As, Cd, Cr, $\mathrm{Cu}, \mathrm{Ni}, \mathrm{Pb}$ and $\mathrm{Zn}$ ) in S. oleracea and its rhizosphere soils with different biochar dosages by using the potential ecological risk index; (2) determine the nutrient relationships between S. oleracea and its rhizosphere soil; and (3) reveal the effects of heavy metal exposure in S. oleracea and its rhizosphere soil with different biochar levels on the health of children and adults. 


\section{Materials and Methods}

\subsection{Site Description}

The soil used in this study was obtained from a karst area of Qingzhen City, Guizhou province, China with coordinates of $106^{\circ} 07^{\prime}-106^{\circ} 32^{\prime} \mathrm{E}, 26^{\circ} 25^{\prime}-26^{\circ} 56^{\prime} \mathrm{N}$. The landform consists of a hilly basin that is dominated by mountains and hills. Qingzhen City comprises $30.5 \%$ mountainous areas, $59 \%$ hilly areas, $5.5 \%$ dam areas and 5\% lakes. It has a humid monsoon climate in the north subtropical zone with an annual rainfall of $1180.9 \mathrm{~mm}$. The annual rainfall ranges from 1021.2 to $1426.9 \mathrm{~mm}$ and decreases from south to north. More than 30 known minerals are present, which include bauxite, haematite, pyrite, coal, and marble, with bauxite being one of the main ore sources for the Guizhou aluminium plant. The Maochang mining area has an area of approximately $80 \mathrm{~km}^{2}$, with a prospective reserve of 210 million tons. It is the largest contiguous mining area among the known bauxite deposits in China.

\subsection{Sampling and Sample Preparation}

The collected lime soil was placed in a shaded shed for natural drying. After the end of drying, it was crushed manually and weighed to verify that it had reached a constant weight. Six levels of biochar content were selected based on previous studies [20]. The total combined masses of the soil and biochar mixtures were always equal to $4000 \mathrm{~g}$ and included the following treatments: only lime soil (C-0), $160 \mathrm{~g}$ of biochar $+3840 \mathrm{~g}$ of lime soil (C-160), $240 \mathrm{~g}$ of biochar $+3760 \mathrm{~g}$ of lime soil (C-240), $320 \mathrm{~g}$ of biochar $+3680 \mathrm{~g}$ of lime soil (C-320), $400 \mathrm{~g}$ of biochar $+3600 \mathrm{~g}$ of lime soil (C-400) and $800 \mathrm{~g}$ of biochar $+3200 \mathrm{~g}$ of lime soil (C-800). Three parallel experiments were performed for each biochar level to obtain reliable data. The S. oleracea seedlings appeared in April 2020 and were planted in pots in June 2020. During this period, the soil in these pots was watered every two days in the morning and evening. The soil and S. oleracea samples were collected in August 2020. The collected lime soil samples were dried, and the contained stones and rhizomes were removed. The treated soil samples were finally sieved with a 100 mesh and were stored and used to determine the heavy metal contents. The collected $S$. oleracea samples were washed with tap water and dried for $48 \mathrm{~h}$. The S. oleracea samples were stored and used to determine their heavy metal contents.

\subsection{Determination of Heavy Metals in Soils and S. oleracea by Inductively Coupled Plasma Atomic Emission Spectrometry}

The soil samples of $0.2000 \mathrm{~g}$ were digested by $\mathrm{HNO}_{3}-\mathrm{HF}-\mathrm{HClO}_{4}(2: 2: 1)$ of $100 \mathrm{~mL}$ in a polytetrafluoroethylene jar and were heated with a heating plate to determine the heavy metal concentrations of $\mathrm{As}, \mathrm{Cd}, \mathrm{Cr}, \mathrm{Cu}, \mathrm{Ni}, \mathrm{Pb}$ and $\mathrm{Zn}$ [21]. Concentrated $\mathrm{HNO}_{3}$ and $\mathrm{HF}$ can destroy the organic structures and silicates in soil, respectively, and concentrated $\mathrm{HNO}_{3}$ causes the samples to be completely oxidized [21]. The S. oleracea samples were digested by $\mathrm{HNO}_{3}-\mathrm{HClO}_{4}$ (3:1) prior to determining their heavy metal contents [22]. Cd and $\mathrm{Pb}$ contents were determined with a ZEEnit $700 \mathrm{p}$ graphite furnace atomic absorption spectrometer (Jena Analytical Instrument Co., Jena, Germany). As, Cr, Cu, Ni and Zn contents were determined with a $5300 \mathrm{v}$ inductively coupled plasma atomic emission spectrometer (Perkin Elmer Company, Waltham, MA, USA). To ensure the precision of the methods, a blank control and three repeated experiments were also used. For each heavy metal, the accuracy and precision of the methods and results were checked by using a certified standard reference material (GSS-3/GBW07403), which was purchased from the State Bureau of Technical Supervision of China. Meanwhile, certified standard reference materials were used for the recovery study, and the recovery rates of the measured heavy metals in the soil samples ranged from $93.2 \%$ to $103.6 \%$. The linear correlation coefficients of all heavy metals were greater than 0.999 , and the relative standard deviations $(n=3)$ varied between $1.0 \%$ and $6.2 \%$. The limits of detection (LODs) and limits of quantification (LOQs) were as follows. As: $\lambda=189.04 \mathrm{~nm}, \mathrm{LOD}=2.15$ and LOQ $=6.45 ; \mathrm{Cd}$ : $\lambda=214.438 \mathrm{~nm}, \mathrm{LOD}=0.05$ and $\mathrm{LOQ}=0.15 ; \mathrm{Cr}: \lambda=267.716 \mathrm{~nm}, \mathrm{LOD}=1.4$ and $\mathrm{LOQ}=4.2$; 
$\mathrm{Cu}: \lambda=324.754 \mathrm{~nm}, \mathrm{LOD}=0.15$ and $\mathrm{LOQ}=0.45 ; \mathrm{Ni}: \lambda=305.082 \mathrm{~nm}, \mathrm{LOD}=2.5$ and LOQ $=7.5 ; \mathrm{Pb}: \lambda=220.351 \mathrm{~nm}, \mathrm{LOD}=2.5$ and $\mathrm{LOQ}=7.5 ;$ and $\mathrm{Zn}: \lambda=213.856 \mathrm{~nm}, \mathrm{LOD}=0.04$ and LOQ $=0.12$. (The LODs were calculated for $1.000 \mathrm{~g}$ quantities of mineralized soil and were diluted to $100 \mathrm{~mL}$ of solution; the LOQs were considered to be three times the LODs.) One gram of soil sample was added to a nitrogen determination tube. A small amount of pure water (e.g., approximately $0.5-1 \mathrm{~mL}$ ) was added to wet the soil sample, and $2 \mathrm{~g}$ of accelerator and $10 \mathrm{~mL}$ of concentrated $\mathrm{H}_{2} \mathrm{SO}_{4}$ were added to the mixtures. After cooking, the $\mathrm{N}$ content in each soil sample was determined using a Kjeldahl analyzer [23]. The P content in each soil sample was determined using GB 9837-88, as proposed by the National Standards of the People's Republic of China. All vessels used were immersed in a $5 \%(v / v)$ nitric acid solution for more than $48 \mathrm{~h}$ before use.

\subsection{Evaluation Method for Soil and S. oleracea}

\subsubsection{Evaluation of Redundancy Analysis}

In order to explore the effects of the soil environmental factors (As, $\mathrm{Cd}, \mathrm{Cr}, \mathrm{Cu}$, $\mathrm{Ni}, \mathrm{Pb}, \mathrm{Zn}$ and $\mathrm{pH}$ ) on the dependent variable (K, $\mathrm{Cr}, \mathrm{As}, \mathrm{Cd}, \mathrm{Pb}, \mathrm{P}, \mathrm{Hg}$ and $\mathrm{N}$ ) in $S$. oleracea, the data of the dependent variable in $S$. oleracea are analyzed by a detrended correspondence analysis. The unimodal distribution or linear distribution is determined by testing the gradient length of the first axis, and thereby select the appropriate ranking analysis method. Canonical correspondence analysis (CCA) is carried out if the gradient length of the first axis is greater than 4 . If the value is less than 3 , redundancy analysis (RDA) is performed. CCA analysis is preferentially used in this study when the value of detrended correspondence analysis is between 3 and 4 [24]. RDA determines the reasons for the variations in the original variables by using the correlations between the original variables and typical variables [24]. RDA describes the proportions of the variation of a dependent variable in the total variations of the dependent variables that are caused by the linear relationships between the dependent variables and typical variables. The RDA analysis of the relationships of the selected indices between soil and S. oleracea was performed using the ape package, vegan package, psych package, and reshape 2 package in the R language (3.6.0) [25].

\subsubsection{Assessment of Potential Ecological Risk Index}

The potential ecological risk index, which was proposed by Hakanson [26], reflects the effect of each pollutant on a specific environment and evaluates the comprehensive impact of multiple pollutants. The formulas for these calculations are as follows:

$$
\begin{gathered}
f=C_{\mathrm{i}} / C_{\mathrm{e}} \\
\mathrm{E}_{\mathrm{r}}^{\mathrm{i}}=T_{\mathrm{i}} \times f_{\mathrm{i}} \\
R I=\sum_{\mathrm{i}=1}^{\mathrm{n}} \mathrm{E}_{\mathrm{r}}^{\mathrm{i}}
\end{gathered}
$$

where $f_{\mathrm{i}}$ is the pollution factor and $C_{\mathrm{i}}$ is the heavy metal concentration of the soil sample, $\mathrm{mg} / \mathrm{kg}$. $C_{\mathrm{e}}$ is the background content (Soil Environment Quality Risk Control Standard for Soil Contamination of Agricultural Land in China, GB15618-2018) of the designated heavy metal. $T_{\mathrm{i}}$ is the toxicity response coefficient of a heavy metal, and the toxicity coefficients of As, Cd, Cr, Cu, Ni, Pb and $\mathrm{Zn}$ are 10, 30, 2, 5, 5, 5 and 1, respectively [26]. E $\mathrm{E}_{\mathrm{r}}^{\mathrm{i}}$ is the potential ecological risk index of a single heavy metal, and RI is the comprehensive potential ecological risk index. The grading standards for $\mathrm{E}_{\mathrm{r}}^{\mathrm{i}}$ and RI values are shown in Table S1 (see Supplementary Material) [26]. 


\subsubsection{Evaluation of Bioaccumulation Factor}

The bioaccumulation factor $(\mathrm{BCF})$ is the ratio of the heavy metal concentration in plants to soil and represents the difficulty of heavy metal migration from soils to plants [27]. The formula is as follows:

$$
\mathrm{BCF}=C_{\text {S. oleracea }} / C_{\text {Soil }}
$$

where $C_{S \text {. oleracea }}$ refers to the heavy metal concentrations in plants, $\mathrm{mg} / \mathrm{kg}$. $C_{\text {Soil }}$ is the corresponding heavy metal concentration in the soil, $\mathrm{mg} / \mathrm{kg}$.

\subsubsection{Health Risk Assessment of Heavy Metals}

In this study, a health risk assessment model, which was developed by the USEPA, was used to assess the effects of heavy metal exposure from soil and S. oleracea on human health. The calculated equation of health risk assessment is exhibited in Table 1 , and $C_{i}$ is the average value of a heavy metal in $S$. oleracea or its rhizosphere soils. $\mathrm{CDI}_{\text {Ingestion-soil, }}$ $\mathrm{CDI}_{\text {dermal contact }}$, and $\mathrm{CDI}_{\text {Inhale-soil }}$ are the chronic daily intakes of heavy metals in soils through ingestion, dermal contact, and inhalation, respectively. $\mathrm{CDI}_{\text {Oral-crop }}$ is the chronic daily intakes of heavy metals in crop through inhalation. $\mathrm{SF}_{\mathrm{ij}}$ is the slope coefficient of the exposure pathway of the carcinogenic heavy metal. $C R_{\mathrm{i}}$ is the single health risk index of a carcinogenic heavy metal. TCR is the total carcinogenic risk index of carcinogenic heavy metals from ingested soil, dermal contact, and inhaled soil. Generally, $C R_{\mathrm{i}}$ and TCR values less than $10^{-6}$ are acceptable. $R_{F} D_{i j}$ is the reference dose of the exposure route for noncarcinogenic heavy metals. HQ is the single health risk index of a noncarcinogenic heavy metal. HQ values lower than 1 indicate that there is no risk to sensitive populations. $\mathrm{HI}$ is the total noncarcinogenic risk index of the heavy metals considered in the present study (in three ways). If the $\mathrm{HI}$ values are less than 1 , there is no chronic noncarcinogenic risk. When the HI values are greater than 1 , it is necessary to treat the contaminated soil. The formulas and definitions of each parameter are shown in Tables S2 and S3 (see Supplementary Material).

Table 1. Calculation formula of health risk assessment model.

\begin{tabular}{|c|c|}
\hline Route of Exposure & Equations \\
\hline Ingestion-soil & $\mathrm{CDI}_{\text {ingestion-soil }}=\frac{\mathrm{C}_{\mathrm{i}} \times \mathrm{IR}_{\text {soil }} \times \mathrm{CF} \times \mathrm{EF} \times \mathrm{ED}}{\mathrm{BW} \times \mathrm{AT}}$ \\
\hline Dermal contact & $\mathrm{CDI}_{\text {dermal-soil }}=\frac{\mathrm{C}_{\mathrm{i}} \times \mathrm{CF} \times \mathrm{SA} \times \mathrm{AF} \times \mathrm{ABS}_{\mathrm{d}} \times \mathrm{EF} \times \mathrm{ED}}{\mathrm{BW} \times \mathrm{AT}}$ \\
\hline Inhale-soil & $\mathrm{CDI}_{\text {inhale }- \text { soil }}=\frac{\mathrm{C}_{\mathrm{i}} \times \mathrm{IR}_{\mathrm{air}} \times \mathrm{EF} \times \mathrm{ED}}{\mathrm{BW} \times \mathrm{AT} \times \mathrm{PEF}}$ \\
\hline Inhale-crop & $\mathrm{CDI}_{\text {inhale }- \text { crop }}=\frac{\mathrm{C}_{\mathrm{i}} \times \mathrm{IR}_{\text {crop }} \times \mathrm{EF} \times \mathrm{ED}}{\mathrm{BW} \times \mathrm{AT}}$ \\
\hline Cancer risk & $C R_{\mathrm{i}}=\sum_{\mathrm{i}=1}^{3} \mathrm{CDI}_{\mathrm{ij}} \mathrm{SF}_{\mathrm{ij}}$ \\
\hline \multirow{2}{*}{ Non-cancer risk } & $\begin{aligned} \mathrm{TCF} & =\sum_{\mathrm{i}=1}^{4} C R_{\mathrm{i}} \\
\mathrm{HQ}_{\mathrm{i}} & =\sum_{\mathrm{j}=1}^{3} \frac{\mathrm{CDI}_{\mathrm{ij}}}{\mathrm{RfD}_{\mathrm{ij}}}\end{aligned}$ \\
\hline & $\mathrm{HI}=\sum_{\mathrm{i}=1}^{4} \mathrm{HQ}_{\mathrm{i}}$ \\
\hline
\end{tabular}

\section{Results}

3.1. Heavy Metal Contents in Soil and Assessment of the Potential Ecological Risks Index with Different Biochar Levels

Before adding biochar to the lime soil, the As content in lime soil was $28.79 \pm 7.7 \mathrm{mg} / \mathrm{kg}$, the $\mathrm{Cd}$ content was $1.56 \pm 0.18 \mathrm{mg} / \mathrm{kg}$, the $\mathrm{Cr}$ content was $115.31 \pm 26 \mathrm{mg} / \mathrm{kg}$, the $\mathrm{Cu}$ content was $71.20 \pm 2.40 \mathrm{mg} / \mathrm{kg}$, the Ni content was $61.97 \pm 6.5 \mathrm{mg} / \mathrm{kg}$, the $\mathrm{Pb}$ content was $25.39 \pm 2.62 \mathrm{mg} / \mathrm{kg}$, the $\mathrm{Zn}$ content was $124.28 \pm 13.25 \mathrm{mg} / \mathrm{kg}$, and the $\mathrm{pH}$ was approximately 6.0. After adding $400 \mathrm{~g}$ of biochar to the lime soil (C-400), the $\mathrm{pH}$ of the soil increased to 7.2 , the As content was $19.30 \pm 2.07 \mathrm{mg} / \mathrm{kg}$, the Cd content 
was $0.75 \pm 0.04 \mathrm{mg} / \mathrm{kg}$, the $\mathrm{Cr}$ content was $58.24 \pm 24.66 \mathrm{mg} / \mathrm{kg}$, the $\mathrm{Cu}$ content was $25.24 \mathrm{mg} / \mathrm{kg} \pm 9.20 \mathrm{mg} / \mathrm{kg}$, the Ni content was $29.85 \pm 2.70 \mathrm{mg} / \mathrm{kg}$, the Pb content was $10.17 \pm 4.24 \mathrm{mg} / \mathrm{kg}$ and the $\mathrm{Zn}$ content was $100.27 \pm 2.55 \mathrm{mg} / \mathrm{kg}$. Overall, with the addition of different biochar levels, the $\mathrm{pH}$ values in the soil increased continuously, and the heavy metal contents in the soils with different carbon levels were reduced (Figure S1, see Supplementary Material).

Table 2 shows the evaluation of heavy metal pollution in lime soil according to the potential ecological risk index. Generally, the levels of heavy metal pollution in lime soil decreased as $\mathrm{Cd}>\mathrm{As}>\mathrm{Cu}>\mathrm{Ni}>\mathrm{Cr}>\mathrm{Pb}>\mathrm{Zn}$, and the levels of $\mathrm{Cd}$ pollution in lime soil were significantly higher than those of the other heavy metals. The order of $\mathrm{E}_{\mathrm{r}}^{\mathrm{i}}(\mathrm{As})$ for the different biochar levels in lime soil was C-160 (8.42) > C-0 (7.20) > C-400 (6.43) > C-320 (6.05) > C-240 (5.06) > C-800 (3.41). At C-400, the Cd pollution in lime soil reached its lowest value, and its $\mathrm{E}_{\mathrm{r}}^{\mathrm{i}}$ value was 75.10. Similarly, at $\mathrm{C}-400$, the $\mathrm{Cu}$ pollution in lime soil was reduced, and the $\mathrm{E}_{\mathrm{r}}^{\mathrm{i}}$ value was 1.26.

Table 2. The evaluation of heavy metal pollution in lime soil by potential ecological risk index.

\begin{tabular}{cccccccc}
\hline Biochar & $\mathbf{E}_{\mathbf{r}}^{\mathbf{i}}(\mathbf{A s})$ & $\mathbf{E}_{\mathbf{r}}^{\mathbf{i}}(\mathbf{C d})$ & $\mathbf{E}_{\mathbf{r}}^{\mathbf{i}}(\mathbf{C r})$ & $\mathbf{E}_{\mathbf{r}}^{\mathbf{i}}(\mathbf{C u})$ & $\mathbf{E}_{\mathbf{r}}^{\mathbf{i}}(\mathbf{N i})$ & $\mathbf{E}_{\mathbf{r}}^{\mathbf{i}}(\mathbf{P b})$ & $\mathbf{E}_{\mathbf{r}}^{\mathbf{i}}(\mathbf{Z n})$ \\
\hline C-0 & 7.20 & 156.42 & 1.54 & 7.12 & 4.43 & 1.41 & 0.62 \\
C-160 & 8.42 & 148.30 & 1.87 & 3.62 & 3.17 & 1.02 & 0.47 \\
C-240 & 5.06 & 88.07 & 0.98 & 1.88 & 1.72 & 0.57 & 0.25 \\
C-320 & 6.05 & 119.52 & 2.18 & 2.87 & 2.52 & 0.85 & 0.41 \\
C-400 & 6.43 & 75.10 & 0.58 & 1.26 & 1.49 & 0.42 & 0.22 \\
C-800 & 3.41 & 108.09 & 1.02 & 2.99 & 2.05 & 2.56 & 0.40 \\
\hline
\end{tabular}

Figure 1 shows the RI values that signify potential ecological risks index. The order of heavy metal risks in lime soil with different biochar levels was C-0 (179) > C-160 (167) $>$ C-320 (134) > C-800 (121) > C-240 (98.5) > C-400 (85.5). Among them, C-0 and C-160 exhibited moderate ecological hazards, while C-320, C-800, C-400 and C-240 showed mild ecological hazards.

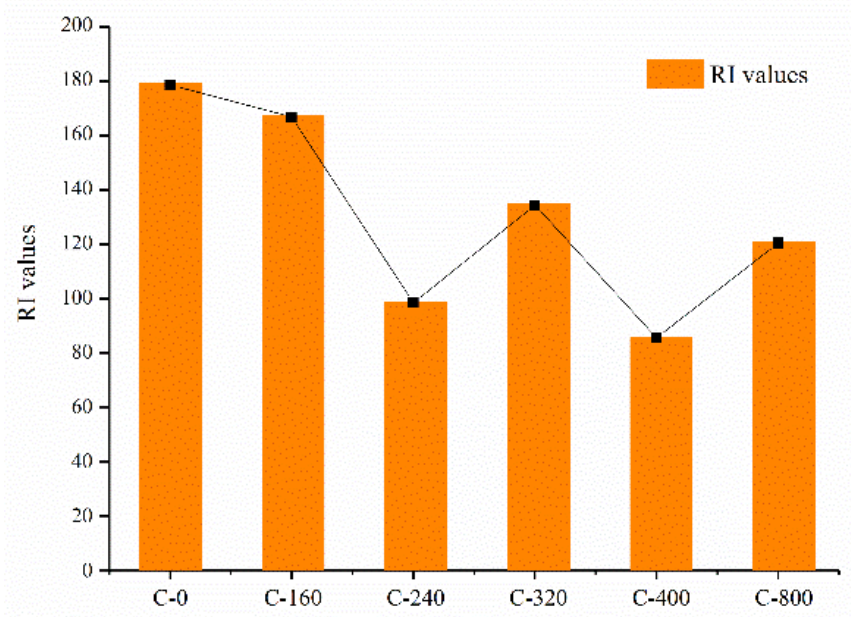

Figure 1. The RI value of potential ecological risk index under the different biochar levels.

\subsection{Heavy Metal Content in S. oleracea and Its Bioaccumulation Factors at Different} Biochar Levels

Figure 2a shows the changes in heavy metal content in S. oleracea at different biochar levels. Generally, the biochar additions had the greatest effects on the Cr contents and lesser effects on the $\mathrm{Cd}$ contents but had no obvious effects on the $\mathrm{Pb}$ or As contents. Figure $2 \mathrm{~b}$ shows the degree of enrichment for $\mathrm{Cr}, \mathrm{As}, \mathrm{Cd}$ and $\mathrm{Pb}$ in S. oleracea. The Cd enrichment ability was highest in S. oleracea, and the BCF values of C-0, C-160, C-240, C-320, C-400 and 
C-800 were $0.52,0.25,0.43,0.24,0.52$ and 0.22 , respectively. Overall, the enrichments of $\mathrm{Cr}$, $\mathrm{As}, \mathrm{Cd}$ and $\mathrm{Pb}$ in $\mathrm{S}$. oleracea did not show any obvious patterns with the addition of biochar.

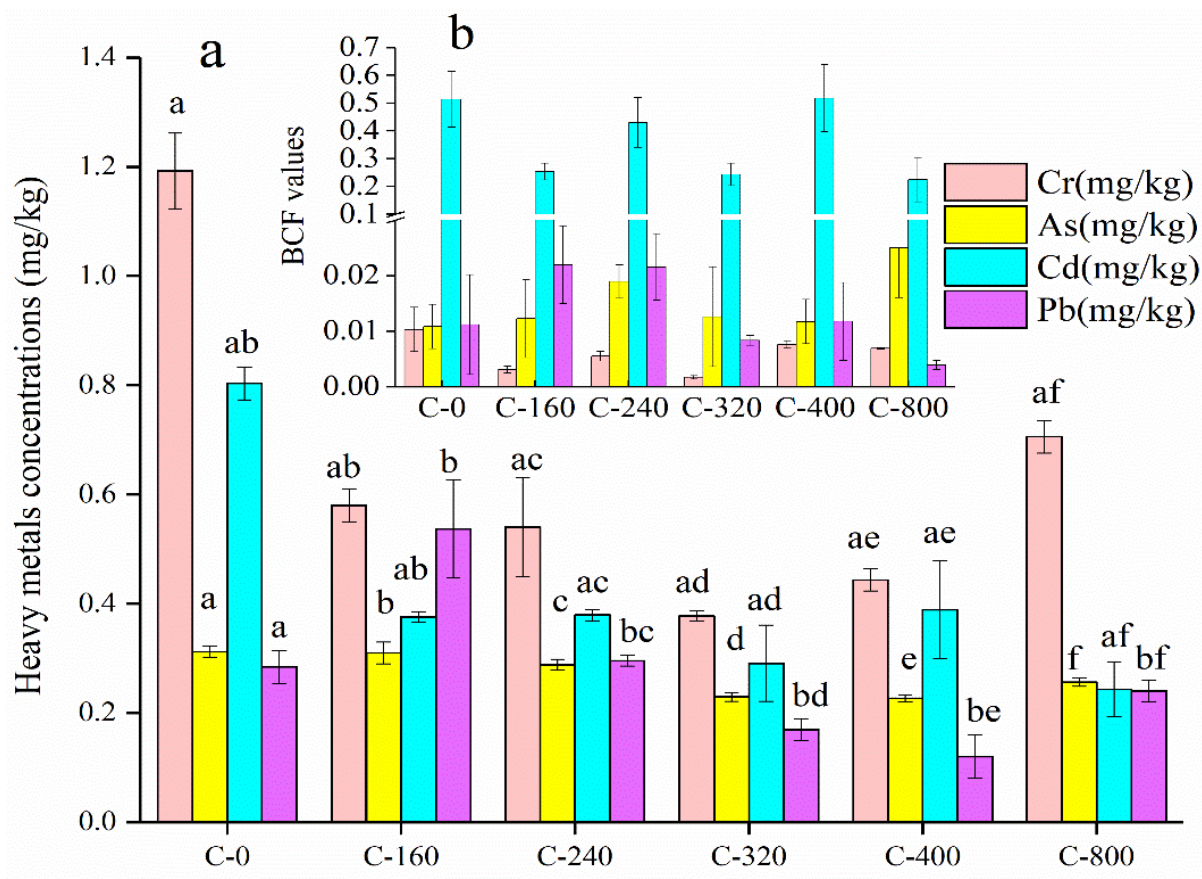

Figure 2. The changes of heavy metal content in S. oleracea (a) and its BCF values (b) under different biochar levels. Note: Mean $\pm \mathrm{SD}, \mathrm{n}=3$. Different superscript letters in the above the column chart represent significant differences between different treatments (ANOVA, $p<0.05$ ).

The DCA analysis results of dependent variables show that the first gradient length is 1.52 , and therefore, RDA was used to clarify the correlation between dependent variables $(\mathrm{K}$, $\mathrm{Cr}, \mathrm{As}, \mathrm{Cd}, \mathrm{Pb}, \mathrm{P}, \mathrm{Hg}$ and $\mathrm{N}$ in S. oleracea) and environmental factors. The total interpretation rate was $90.12 \%$ in the developed RDA model, including $54.22 \%$ of Axis I and $35.90 \%$ of Axis II (Figure 3). The quadrant of the arrow indicates the positive and negative correlation between the environmental factor and the sorting axis. The smaller included angle between the arrow and the sorting axis (or the environmental and dependent factors) represents the higher correlation. The length of the arrow connecting line represents the effect of an environmental factor on the distribution of the selected element contents in S. oleracea. The longer the connecting line, the greater the impact of this environmental factor on the distribution of the selected element contents in S. oleracea was. According to the length of the arrow connecting line, $\mathrm{pH}, \mathrm{Pb}, \mathrm{Zn}, \mathrm{Cd}$ and $\mathrm{Ni}$ had a higher effect on the distribution of $\mathrm{K}, \mathrm{Cr}, \mathrm{As}, \mathrm{Cd}, \mathrm{Pb}, \mathrm{P}, \mathrm{Hg}$ and $\mathrm{N}$ in S. oleracea. Among them, the $\mathrm{pH}$ values of the lime soil was positively correlated with the $\mathrm{Pb}, \mathrm{P}$ and $\mathrm{K}$ contents and negatively correlated with the $\mathrm{As}, \mathrm{Cr}, \mathrm{Hg}, \mathrm{Cd}$ and $\mathrm{N}$ contents in S. oleracea. The positive correlation implies that the $\mathrm{Pb}, \mathrm{P}$ and $\mathrm{K}$ contents in S. oleracea decreased with increasing soil $\mathrm{pH}$ levels. The soil $\mathrm{pH}$ levels exhibited a weak correlation with the As, $\mathrm{Cr}$ and $\mathrm{Hg}$ contents in S. oleracea, which indicates that the changes in soil $\mathrm{pH}$ had little effect on the $\mathrm{As}, \mathrm{Cr}$ and $\mathrm{Hg}$ contents in plants. In addition, $\mathrm{Pb}, \mathrm{Zn}$ and $\mathrm{Cd}$ concentrations in soil were positively correlated with $\mathrm{Pb}, \mathrm{As}, \mathrm{Cr}$ and $\mathrm{Hg}$ in S. oleracea. $\mathrm{Zn}$ concentrations in soil had positive correlation with $\mathrm{Cd}, \mathrm{Pb}, \mathrm{As}, \mathrm{Cr}$ and $\mathrm{Hg}$ in S. oleracea. Ni content in soil was positively correlated with $\mathrm{Cd}, \mathrm{Hg}, \mathrm{Cr}$, As in S. oleracea. 


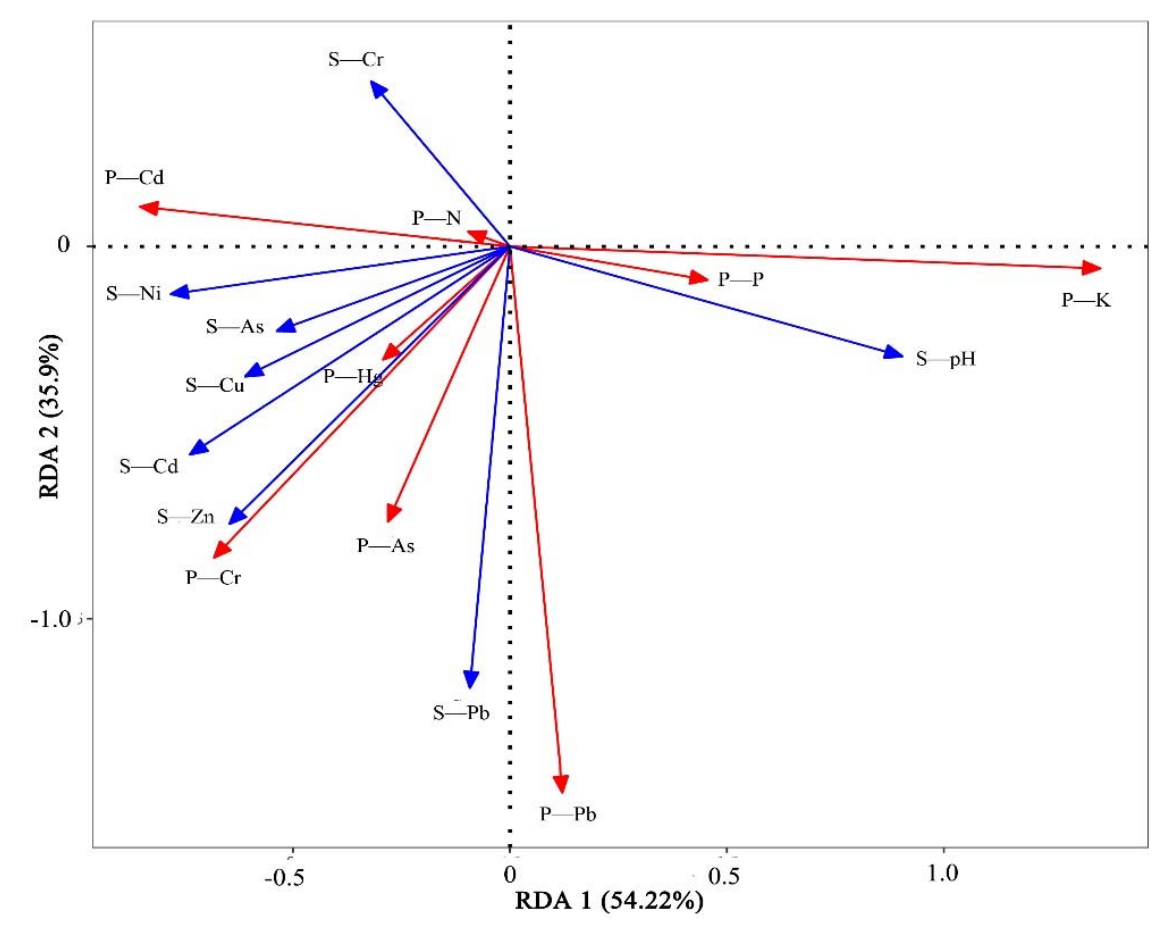

Figure 3. RDA analysis of elements in soil and S. oleracea. (Note: $\mathrm{S}$ and $\mathrm{P}$ in front represent soil and plant, respectively.).

\subsection{Health Risk Assessment}

3.3.1. Assessment of Noncarcinogenic Health Risks for Heavy Metals in Lime Soil with Different Biochar Levels

Table 3 compares the HQ and HI values of heavy metals in adults and children who were exposed to oral intake, skin contact and respiratory intake. The HI values for levels C-0, C-160 and C-320 were greater than 1 for children, and the order for heavy metal exposure in the lime soil samples with different biochar levels was C-800 >C-400 $\approx \mathrm{C}-240$ for both adults and children. The exposure risk due to heavy metals in lime soil for C-0 was greatest for adults and children and was the most harmful for children. However, after adding biochar, the risk for adults and children was alleviated, except for C-160. The $\mathrm{HQ}$ values of the heavy metals that were detected for different biochar levels were less than 1 , and it was calculated that the effects of the three exposure routes on the HQ values for adults and children decreased in the order oral intake $>$ skin contact $>$ respiratory inhalation. Through these three exposure routes, the HQ values for the six different biochar levels were $\mathrm{As}>\mathrm{Cr}>\mathrm{Cu}>\mathrm{Ni}>\mathrm{Cd}>\mathrm{Zn}$. Among them, As and $\mathrm{Cr}$ were the most important components of the carcinogenic risk from lime soil.

\subsubsection{Assessment of Carcinogenic Health Risks for Heavy Metals in Lime Soil with} Different Biochar Levels

Table 4 shows the CR and TCR values of lime soil containing As, Cd, $\mathrm{Cr}$ and $\mathrm{Ni}$ for adults and children for different biochar levels. According to the risk analysis of carcinogenic heavy metals on human health, the CR(As) and CR(Cd) values in lime soil with different biochar levels were higher than the maximum acceptable level $\left(10^{-6}\right)$ that is recommended by the USEPA. It can be concluded that heavy metal exposure from lime soil with different biochar levels presents a significant carcinogenic health risk. The TCR values at different biochar levels for children were higher than those for adults, and both sets of values were higher than the maximum acceptable levels that are recommended by the USEPA $\left(10^{-6}\right)$. Therefore, exposure to heavy metals in lime soil with the six biochar levels poses a serious threat to the health of children, and there is an unacceptable risk of carcinogenesis for adults. 
Table 3. The HQ and HI values of heavy metals exposed in soil for adults and children.

\begin{tabular}{ccccccccc}
\hline \multirow{2}{*}{ Biochar } & Age & \multicolumn{7}{c}{ HQ } \\
\cline { 3 - 7 } & & As & Cd & Cr & Cu & Ni & Zn & HI \\
\hline \multirow{2}{*}{ C-0 } & Adult & 0.1627 & 0.0027 & 0.0432 & 0.0035 & 0.0052 & 0.0007 & 0.218 \\
& Children & 0.9612 & 0.0157 & 0.245 & 0.0203 & 0.031 & 0.0042 & 1.2774 \\
\hline \multirow{2}{*}{ C-160 } & Adult & 0.1428 & 0.0025 & 0.07 & 0.0036 & 0.0054 & 0.0007 & 0.225 \\
& Children & 0.8437 & 0.0149 & 0.3963 & 0.0206 & 0.0317 & 0.004 & 1.3112 \\
\hline C-240 & Adult & 0.0858 & 0.0015 & 0.0367 & 0.0018 & 0.0029 & 0.0004 & 0.1291 \\
& Children & 0.5072 & 0.0088 & 0.2082 & 0.0107 & 0.0172 & 0.0021 & 0.7542 \\
\hline C-320 & Adult & 0.1026 & 0.002 & 0.0816 & 0.0028 & 0.0043 & 0.0006 & 0.1939 \\
& Children & 0.6064 & 0.012 & 0.4624 & 0.0163 & 0.0252 & 0.0034 & 1.1257 \\
\hline \multirow{2}{*}{ C-400 } & Adult & 0.109 & 0.0013 & 0.0218 & 0.0012 & 0.0025 & 0.0003 & 0.1361 \\
& Children & 0.6443 & 0.0075 & 0.1238 & 0.0072 & 0.0149 & 0.0019 & 0.7996 \\
\hline \multirow{2}{*}{ C-800 } & Adult & 0.0578 & 0.0018 & 0.0382 & 0.0029 & 0.0035 & 0.0006 & 0.1048 \\
& Children & 0.3415 & 0.0108 & 0.2163 & 0.017 & 0.0205 & 0.0034 & 0.6095 \\
\hline
\end{tabular}

Table 4. The CR and TCR values of heavy metals in soil exposed for adults and children.

\begin{tabular}{|c|c|c|c|c|c|c|}
\hline \multirow{2}{*}{ Biochar } & \multirow{2}{*}{ Age } & \multicolumn{4}{|c|}{ CR } & \multirow{2}{*}{ TCR } \\
\hline & & $\mathrm{Cd}$ & As & $\mathrm{Cr}$ & $\mathbf{N i}$ & \\
\hline \multirow[t]{2}{*}{$\mathrm{C}-0$} & Adult & $5.84 \times 10^{-6}$ & $2.63 \times 10^{-5}$ & $5.16 \times 10^{-8}$ & $1.97 \times 10^{-9}$ & $3.22 \times 10^{-5}$ \\
\hline & Children & $8.22 \times 10^{-6}$ & $3.71 \times 10^{-5}$ & $1.83 \times 10^{-7}$ & $5.55 \times 10^{-9}$ & $4.55 \times 10^{-5}$ \\
\hline \multirow[t]{2}{*}{ C-160 } & Adult & $5.54 \times 10^{-6}$ & $2.31 \times 10^{-5}$ & $8.35 \times 10^{-8}$ & $2.02 \times 10^{-9}$ & $2.87 \times 10^{-5}$ \\
\hline & Children & $7.80 \times 10^{-6}$ & $3.25 \times 10^{-5}$ & $2.97 \times 10^{-7}$ & $5.68 \times 10^{-9}$ & $4.06 \times 10^{-5}$ \\
\hline \multirow[t]{2}{*}{ C-240 } & Adult & $3.29 \times 10^{-6}$ & $1.39 \times 10^{-5}$ & $4.39 \times 10^{-8}$ & $1.09 \times 10^{-9}$ & $1.72 \times 10^{-5}$ \\
\hline & Children & $4.63 \times 10^{-6}$ & $1.96 \times 10^{-5}$ & $1.56 \times 10^{-7}$ & $3.08 \times 10^{-9}$ & $2.43 \times 10^{-5}$ \\
\hline \multirow[t]{2}{*}{ C-320 } & Adult & $4.47 \times 10^{-6}$ & $1.66 \times 10^{-5}$ & $9.74 \times 10^{-8}$ & $1.60 \times 10^{-9}$ & $2.12 \times 10^{-5}$ \\
\hline & Children & $6.28 \times 10^{-6}$ & $2.34 \times 10^{-5}$ & $3.46 \times 10^{-7}$ & $4.52 \times 10^{-9}$ & $3.00 \times 10^{-5}$ \\
\hline \multirow[t]{2}{*}{ C-400 } & Adult & $2.81 \times 10^{-6}$ & $1.76 \times 10^{-5}$ & $2.61 \times 10^{-8}$ & $9.49 \times 10^{-10}$ & $2.05 \times 10^{-5}$ \\
\hline & Children & $3.95 \times 10^{-6}$ & $2.48 \times 10^{-5}$ & $9.27 \times 10^{-8}$ & $2.68 \times 10^{-9}$ & $2.89 \times 10^{-5}$ \\
\hline \multirow[t]{2}{*}{ C-800 } & Adult & $4.04 \times 10^{-6}$ & $9.35 \times 10^{-6}$ & $4.56 \times 10^{-8}$ & $1.30 \times 10^{-9}$ & $1.34 \times 10^{-5}$ \\
\hline & Children & $5.68 \times 10^{-6}$ & $1.32 \times 10^{-5}$ & $1.62 \times 10^{-7}$ & $3.67 \times 10^{-9}$ & $1.90 \times 10^{-5}$ \\
\hline
\end{tabular}

3.3.3. Assessment of Noncarcinogenic Health Risks due to Heavy Metals in S. oleracea with Different Biochar Levels

Table 5 shows the HQ and HI values for adults and children that result from heavy metals in S. oleracea. The order of the $\mathrm{HQ}(\mathrm{Cd})$ values for adults and children was $\mathrm{C}-0>$ C-400 > C $-240>$ C $-160>$ C $-320>C-800$. The order of the HQ(As) values for adults and children was C- $0>\mathrm{C}-160>\mathrm{C}-240>\mathrm{C}-800>\mathrm{C}-320>\mathrm{C}-400$. The order of the HQ(Cr) values for adults and children was $\mathrm{C}-0>\mathrm{C}-800>\mathrm{C}-160>\mathrm{C}-240>\mathrm{C}-400>\mathrm{C}-320$. The order of the $\mathrm{HQ}(\mathrm{Ni})$ values for adults and children was $\mathrm{C}-160>\mathrm{C}-240>\mathrm{C}-0>\mathrm{C}-800>\mathrm{C}-320>$ C-400. The order of the HI values for adults and children was C- $0>$ C-160 $>$ C-240 $>$ C-800 $>\mathrm{C}-400>\mathrm{C}-320$. Cr had a significant effect on the noncarcinogenic risk of S. oleracea, and the HQ thresholds for heavy metals in S. oleracea with different biochar levels were greater for children than for adults and were above the acceptable levels for human health $\left(10^{-6}\right)$. These results indicate that the intake of $S$. oleracea planted in the studied soil poses a great threat to human health. 
Table 5. The HQ and HI values of heavy metals exposed in S. oleracea for adults and children.

\begin{tabular}{ccccccc}
\hline \multirow{2}{*}{ Biochar } & Age & \multicolumn{5}{c}{ HQ } \\
\cline { 3 - 6 } & & Cd & As & Cr & Ni & HI \\
\hline \multirow{2}{*}{ C-0 } & Adult & 4.09 & 1.59 & 6.06 & 1.45 & 13.19 \\
& Children & 9.29 & 3.61 & 13.78 & 3.29 & 29.97 \\
\hline \multirow{2}{*}{ C-160 } & Adult & 1.91 & 1.58 & 2.95 & 2.73 & 9.17 \\
& Children & 4.35 & 3.58 & 6.70 & 6.21 & 20.84 \\
\hline \multirow{2}{*}{ C-240 } & Adult & 1.93 & 1.47 & 2.75 & 1.50 & 7.65 \\
& Children & 4.38 & 3.33 & 6.25 & 3.42 & 17.38 \\
\hline \multirow{2}{*}{ C-320 } & Adult & 1.48 & 1.17 & 1.92 & 0.86 & 5.43 \\
& Children & 3.36 & 2.65 & 4.37 & 1.96 & 12.35 \\
\hline \multirow{2}{*}{ C-400 } & Adult & 1.98 & 1.15 & 2.26 & 0.61 & 6.00 \\
& Children & 4.50 & 2.62 & 5.13 & 1.39 & 13.63 \\
\hline \multirow{2}{*}{ C-800 } & Adult & 1.24 & 1.31 & 3.59 & 1.22 & 7.36 \\
& Children & 2.81 & 2.97 & 8.16 & 2.78 & 16.71 \\
\hline
\end{tabular}

3.3.4. Assessment of Carcinogenic Health Risks due to Heavy Metals in S. oleracea with Different Biochar Levels

Table 6 shows the CR and TCR values for adults and children due to As, $\mathrm{Cd}, \mathrm{Cr}$, and $\mathrm{Ni}$ contents in S. oleracea with different biochar levels. As indicated by the risk analysis of the effects of carcinogenic heavy metals on human health, As and $\mathrm{Cr}$ in S. oleracea were the main factors that impacted the CR and TCR values, and the order of these indices for the different biochar levels was C- $0>\mathrm{C}-160>\mathrm{C}-240>\mathrm{C}-800>\mathrm{C}-400 \approx \mathrm{C}-320$. The threat to children is greater than that to adults, which itself is higher than the maximum acceptable level $\left(10^{-6}\right)$, as recommended by the USEPA, and the values represent unacceptable cancer risks.

Table 6. The CR and TCR values of heavy metals exposed in S. oleracea for adults and children.

\begin{tabular}{|c|c|c|c|c|c|}
\hline \multirow{2}{*}{ Biochar } & \multirow{2}{*}{ Age } & \multicolumn{3}{|c|}{ CR } & \multirow{2}{*}{ TCR } \\
\hline & & $\mathrm{Cd}$ & As & $\mathrm{Cr}$ & \\
\hline \multirow[t]{2}{*}{ C-0 } & Adult & $1.54 \times 10^{-5}$ & $2.40 \times 10^{-3}$ & $3.03 \times 10^{-3}$ & $5.45 \times 10^{-3}$ \\
\hline & Children & $3.53 \times 10^{-5}$ & $5.44 \times 10^{-3}$ & $2.00 \times 10^{-4}$ & $5.68 \times 10^{-3}$ \\
\hline \multirow[t]{2}{*}{$C-160$} & Adult & $7.22 \times 10^{-6}$ & $2.37 \times 10^{-3}$ & $1.47 \times 10^{-3}$ & $3.85 \times 10^{-3}$ \\
\hline & Children & $1.65 \times 10^{-5}$ & $5.39 \times 10^{-3}$ & $9.71 \times 10^{-5}$ & $5.50 \times 10^{-3}$ \\
\hline \multirow[t]{2}{*}{ C-240 } & Adult & $7.29 \times 10^{-6}$ & $2.20 \times 10^{-3}$ & $1.37 \times 10^{-3}$ & $3.58 \times 10^{-3}$ \\
\hline & Children & $1.67 \times 10^{-5}$ & $5.01 \times 10^{-3}$ & $9.05 \times 10^{-5}$ & $5.12 \times 10^{-3}$ \\
\hline \multirow[t]{2}{*}{ C-320 } & Adult & $5.59 \times 10^{-6}$ & $1.75 \times 10^{-3}$ & $9.60 \times 10^{-4}$ & $2.72 \times 10^{-3}$ \\
\hline & Children & $1.28 \times 10^{-5}$ & $4.00 \times 10^{-3}$ & $6.32 \times 10^{-5}$ & $4.08 \times 10^{-3}$ \\
\hline \multirow[t]{2}{*}{ C-400 } & Adult & $7.48 \times 10^{-6}$ & $1.73 \times 10^{-3}$ & $1.12 \times 10^{-3}$ & $2.86 \times 10^{-3}$ \\
\hline & Children & $1.71 \times 10^{-5}$ & $3.94 \times 10^{-3}$ & $7.4310^{-5}$ & $4.03 \times 10^{-3}$ \\
\hline \multirow[t]{2}{*}{ C-800 } & Adult & $4.67 \times 10^{-6}$ & $1.96 \times 10^{-3}$ & $1.80 \times 10^{-3}$ & $3.76 \times 10^{-3}$ \\
\hline & Children & $1.07 \times 10^{-5}$ & $4.47 \times 10^{-3}$ & $1.18 \times 10^{-4}$ & $4.60 \times 10^{-3}$ \\
\hline
\end{tabular}

\section{Discussion}

That $\mathrm{pH}$ values in soil increase with the addition of different proportions of biochar has already been reported [14], and this phenomenon in the present study is therefore not significant. Liu et al. [28] report the effect of lychee biochar on the remediation of heavy metal contaminated soil that was used to grow sunflowers. The sunflower plants significantly decreased the $\mathrm{Pb}, \mathrm{Cd}, \mathrm{As}$, and $\mathrm{Zn}$ concentrations in contaminated soil $(p<0.05)$, with decreases of $12.4,11.0,4.35$, and $8.17 \%$, respectively, when compared with soil samples without sunflowers planted. The addition of biochar to heavy metal contaminated 
soil significantly enhanced the heavy metal remediation that was affected by sunflowers. Chen et al. [29] studied whether Cd bioavailability was affected in soils containing biochar and crop straw. The results show that biochar amendments enhanced the peanut biomass and physiological quality, and biochar had a greater impact on immobilizing $\mathrm{Cd}$ in the soil. In addition, biochar was more significant $(p<0.05)$ in decreasing the $\mathrm{Cd}$ bioavailability and improving the biomass of peanuts. Wang et al. [30] demonstrated a facile pyrolytic synthesis of biochar/ZnO passivators, their use in $\mathrm{Cu}(\mathrm{II})$ immobilization, and the mechanism of that process. Biochar was prepared from waste pomelo peel that was combined with $\mathrm{ZnO}$ to immobilize $\mathrm{Cu}$ (II) in contaminated soil, and the maximum adsorption capacity was $216.37 \mathrm{mg} / \mathrm{g}$. In addition, mechanistic investigations indicated that $\mathrm{Cu}$ (II) bound to biochar/ $\mathrm{ZnO}$ was primarily in a nonbioavailable state $(75.6 \%)$. The heavy metal concentrations in lime soil were reduced by biochar, something that may be caused by several mechanisms including $\Pi-\Pi$ electron interactions, ion exchange, surface complexation, precipitation reactions, and redox reactions [31]. Especially for the $\Pi-\Pi$ interactions, the biochar surface is highly aromatic and has dense $\Pi$ electron clouds, which easily combine with the $\Pi$-bonds of heavy metals. The $\Pi$ electrons on the biochar surface can serve as electron donors and interact with metal electron acceptors with d-orbitals and form $\Pi-\Pi$ electron interactions [32]. Lin et al. [33] revealed the mechanism for the adsorption of $\mathrm{Cd}^{2+}$ on corn straw scale biochar samples that were produced at $350{ }^{\circ} \mathrm{C}$ and $700{ }^{\circ} \mathrm{C}$, and cation- $\Pi$ interactions were one of the main mechanisms. Cation- $\Pi$ interactions are relatively complex and mainly depend on the degree of aromaticity on the biochar surface and on the properties of the metals. The degree of biochar aromaticity gives rise to a common aromatic structure. The stronger the electron donor ability of the biochar and the lower the $d$ orbital energies of the metals are, the more obvious the effect.

Ion exchange may be the other main reason for the different adsorption capacities of biochar for heavy metals in soils. The adsorption capacities of different metal ions depend on their own holding forces; hence, the adsorption capacity of biochar for ions is different if multiple metal ions coexist. In addition, depending on the raw materials and temperatures employed, different amounts of oxygen-containing functional groups, such as $-\mathrm{OH},-\mathrm{CO},-\mathrm{O}$, and $-\mathrm{COOH}$, may form on the biochar surfaces [28]. It has been reported that the functional groups of biochar have a high adsorption affinity for $\mathrm{Cu}$. Therefore, Jiang et al. [34] further explored the adsorption and fixation of $\mathrm{Cu}$ by rice straw biochar and evaluated the effects of the alkalinity levels and functional groups on the fixation of $\mathrm{Cu}$. The results show that both the alkalinity and oxygen-containing functional groups lead to $\mathrm{Cu}$ fixation; however, adsorption by the oxygen-containing biochar functional groups was the main mechanism. Additionally, Jiang et al. [35] studied the effects of biochar on soil surface charges and on the adsorption of $\mathrm{Pb}^{2+}$ through batch experiments. They found that electrostatic and non electrostatic interactions coexisted in the adsorption process and that the formation of complexes between the functional groups and $\mathrm{Pb}^{2+}$ was the main mechanism for adsorption. These mechanisms may be the other reason for the different heavy metal adsorption capacities of biochar that were determined in the present study.

Our study shows that the heavy metal concentrations in soils decreased continuously with the addition of increased biochar amounts, and this tendency terminated with the addition of $400 \mathrm{~g}$ of biochar. Several researchers have also found that additional biochar contents and the adsorption of heavy metals are often positively correlated; however, the adsorption capacity for heavy metals reaches saturation when the additional amount of biochar reaches a certain value [36,37]. Gan et al. [38] used 10, 30, 50, 70 and $100 \mathrm{~g} / \mathrm{kg}$ of straw biochar in a heavily polluted area of an electroplating plant to determine the changes in the total amounts and speciation of heavy metals in soil. They found variations in the stabilizing effects of different biochar levels on heavy metals. Liu et al. [39] used several different crops as raw materials to prepare biochars and studied the adsorption of $\mathrm{Cd}^{2+}$ and $\mathrm{Pb}^{2+}$ in solution. Their results indicate that the removal efficiency for $\mathrm{Pb}$ increased with increasing amounts of biochar materials that were produced by corn straw, wheat straw and peanut shells. Additionally, the $\mathrm{pH}$ levels were different for different 
soil types, which can significantly affect the forms of heavy metals that are present and the surface charge distributions of biochar [40]. Biochar is normally alkaline and could thus increase the soil $\mathrm{pH}$ levels at higher application rates, particularly in acidic soils, which is consistent with the results of our study. It was also found that such $\mathrm{pH}$ changes could in turn facilitate the hydrolysis of heavy metals, which would thereby enhance their adsorption by soil and accelerate the transformations of the oxidizable and residual fractions of heavy metals [41]. Due to the differences in raw materials, technologies and pyrolysis conditions used, biochar shows variations in its physical and chemical properties, such as structure and particle size distribution, pore volume, apparent density, specific surface area, $\mathrm{pH}$, volatile matter content, ash content and water holding capacity [42]. The raw materials and pyrolysis temperatures that are used to synthesize biochar are significant factors that affect the characteristics and properties of biochar. The mean particle sizes and size distributions of biochar are dependent on the properties of the raw materials, and the particle size of biochar determines the surface area [42,43]. Furthermore, the present study demonstrates that the amount of biochar applied is an important factor that determines the different adsorption capacities for heavy metals, especially in soils that are contaminated with mixtures of heavy metals.

The growth and development of plants depend on a fine soil environment. However, there are numerous obstacles in soil that can restrict the growth of plants in nature. Biochar applications can significantly increase soil $\mathrm{pH}$, which thus reduces the contents of exchangeable metals, e.g., $\mathrm{Al}, \mathrm{Cu}$ and $\mathrm{Fe}$, and increases the availability of essential elements, e.g., N, P, K, Ca, and Mg [44]. This mechanism explains why the soil pH was positively correlated with the $\mathrm{K}$ and $\mathrm{P}$ contents in plants, as is shown by the redundancy analysis in the present study. Biochar can limit the damage that is caused by elements that are harmful to $S$. oleracea growth. Therefore, the $\mathrm{pH}$ values of the lime soil were positively correlated with the $\mathrm{Pb}, \mathrm{P}$ and $\mathrm{K}$ contents and negatively correlated with the $\mathrm{As}, \mathrm{Cr}, \mathrm{Hg}, \mathrm{Cd}$ and $\mathrm{N}$ contents in S. oleracea. Thus, the BCF values of $\mathrm{Cr}, \mathrm{As}, \mathrm{Cd}$ and $\mathrm{Pb}$ decreased as the $\mathrm{pH}$ values of the lime soil increased with added biochar. Khan et al. [45] report that the application of $\mathrm{HWB}$ decreased the concentrations of $\mathrm{Cr}, \mathrm{Zn}, \mathrm{Cu}, \mathrm{Mn}$, and $\mathrm{Pb}$ in cilantro by $25.5 \%, 37.1 \%, 42.5 \%, 34.3 \%$, and $36.2 \%$, respectively, when compared with the control. In $S$. oleracea, the concentration reductions were $\mathrm{Cr} 75.0 \%, \mathrm{Zn} 24.1 \%, \mathrm{Cu} 70.1 \%, \mathrm{Mn} 78.0 \%$, and $\mathrm{Pb} 50.5 \%$ when compared with those of the control. The bioaccumulation factor results also indicate that hardwood biochar inhibited the bioaccumulation of selected heavy metals in cilantro and S. oleracea, which thus reduced the health risks. Song et al. [46] demonstrated that biochars are rich in nutrient contents and improved garlic yields. Sewage sludge is a suitable biochar resource, especially for biochar that is produced at $450^{\circ} \mathrm{C}$; this sludge has rich micropores, relatively stable functional groups in its structure and rugged surfaces that provide good contact with soil, all of which are conducive to its use as biochar. Zheng et al. [47] revealed the effects of bean stalk and rice straw biochars on the bioavailability of metal(loid)s in soil and their accumulation in rice plants. Both biochars significantly decreased the $C d$ concentrations in iron plaque (35-81\%), roots (30-75\%), shoots (43-79\%) and rice grains $(26-71 \%)$. Following the biochar additions, the zinc concentrations in the roots and shoots decreased by 25.0-44.1 and 19.9-44.2\%, respectively. In addition, biochar can enhance the uptake of nutrients and promote plant growth. Overall, biochar has a low content of mineral nutrients, and its ability to directly supply nutrients is limited. The promotion of crop growth by biochar is mainly due to the improvements in the physical and chemical properties of soil, enhanced soil nutrient availability, and changes in soil structure [48].

In assessing the potential ecological risk index by using toxicity coefficients, the C-0 and C-160 levels presented moderate ecological hazards, while the C-320, C-800, C-400 and C-240 levels presented mild ecological hazards. The method of introducing toxicity coefficients focuses on evaluating the potential risk of heavy metal toxicity to the environment. However, although the potential ecological risk index is used to evaluate the pollution status of heavy metals in soil, it is impossible to comprehensively evaluate 
the adverse human health effects that are caused by harmful environmental factors [19]. The carcinogenic and noncarcinogenic health risk models, which were developed by the USEPA, were used to link environmental pollution sources with the health of exposed humans by using certain evaluation criteria and technical routes [49]. In the present study, the HI, HQ, CR and TCR values indicate that exposure to the heavy metals in lime soil and S. oleracea pose a serious threat to human health and present an unacceptable cancer risk, with children being more threatened than adults. Zhang et al. [50] investigated the characteristics of heavy metal pollution and health risk evaluations for soils and vegetables in various functional areas of lead-zinc tailings ponds. The heavy metal pollutants in the soils and vegetables in the studied tailings area posed a serious threat to the surrounding ecological environment and to the health of the residents. Lin et al. [33] report that the noncarcinogenic and carcinogenic effects that were caused by heavy metal exposure were regarded as acceptable (except for those in Lingyun County). Lingyun County soils should receive more attention due to the unacceptable levels of carcinogenic risk. As, $\mathrm{Cd}, \mathrm{Hg}$, and $\mathrm{Cr}$ were regarded as the priority control metals, which is in accordance with our results. Sawut et al. [51] demonstrated that when considering the noncarcinogenic risks for children, the HI values were larger than 1 in all areas, which indicates that local children face a higher potential noncarcinogenic risk. In addition, the carcinogenic risk that results from dermal contact with vegetable bases does not pose a high risk for residents. For children, the carcinogenic risks posed by As through inhalation and ingestion are the main exposure pathways. The TCR values for adults and children were $>1 \times 10^{-4}$ (unitless) in Sishihu village, Anningqu town, and Qinggedahu village, and this degree of carcinogenic risk is unacceptable. The serious threats to human health that are caused by heavy metals in lime soils and S. oleracea may be due to soil materials that are collected from polluted areas.

\section{Conclusions}

Our results demonstrate that the levels of heavy metal pollution in lime soil decreased in the order $\mathrm{Cd}>\mathrm{As}>\mathrm{Cu}>\mathrm{Ni}>\mathrm{Cr}>\mathrm{Pb}>\mathrm{Zn}$, and that the level of $\mathrm{Cd}$ pollution in lime soil was significantly higher than those of other heavy metals. The order of heavy metal risks in lime soil with different biochar levels was C-0 (179) > C-160 (167) > C-320 (134) > C-800 (121) > C-240 (98.5) > C-400 (85.5). Among them, the C-0 and C-160 levels exhibited moderate ecological hazards, while the C-320, C-800, C-400 and C-240 levels indicated mild ecological hazards. The $\mathrm{pH}$ values of the lime soil were positively correlated with the $\mathrm{Pb}$, $\mathrm{P}$ and $\mathrm{K}$ contents and negatively correlated with the $\mathrm{As}, \mathrm{Cr}, \mathrm{Hg}, \mathrm{Cd}$ and $\mathrm{N}$ contents in $\mathrm{S}$. oleracea. $\mathrm{Pb}, \mathrm{Zn}$ and $\mathrm{Cd}$ concentrations in soil were positively correlated with $\mathrm{Pb}, \mathrm{As}, \mathrm{Cr}$ and $\mathrm{Hg}$ in S. oleracea. $\mathrm{Zn}$ concentrations in soil had positive correlations with $\mathrm{Cd}, \mathrm{Pb}, \mathrm{As}$, $\mathrm{Cr}$ and $\mathrm{Hg}$ in S. oleracea.

The evaluation of the carcinogenic and noncarcinogenic risk levels based on the HI, $\mathrm{HQ}, \mathrm{CR}$ and TCR values indicate that exposure to heavy metals in lime soil and S. oleracea pose a serious threat to human health and create an unacceptable cancer risk with children under more threat than adults. Heavy metal pollution of S. oleracea and its rhizosphere lime soil in karst areas still poses a threat to human health after adding biochar. The relevant local departments need to implement more active measures to solve the excessive heavy metal contents in the local soil and vegetables of these karst regions. Additionally, the aging of biochar in soil is a common phenomenon and microbes are of importance in the soil-to-vegetable system. This is a preliminary study, which is prepared for the next work to alleviate the aging of biochar and investigate the role of microbes in the migration of heavy metals in karst soil.

Supplementary Materials: The following are available online at https:/ /www.mdpi.com/article/10 .3390 / su131910843/s1. Table S1: The grading standards of $\mathrm{E}_{\mathrm{r}}^{\mathrm{i}}$ and RI values. Table S2: Health risk assessment exposure parameters. Table S3: Model parameters RfD and SF values. Figure S1: The contents of heavy metals (a) and magnified $\mathrm{Cd}(\mathrm{b})$ in soil under different carbon levels. 
Author Contributions: Writing—original draft preparation, G.X.; writing-review, G.X., X.W., S.L. All authors have read and agreed to the published version of the manuscript.

Funding: This work was supported by the Program for the National Natural Science Foundation of China-Guangdong United Foundation (U1501235).

Institutional Review Board Statement: Not applicable.

Informed Consent Statement: Not applicable.

Data Availability Statement: Data from this paper are available from Google Scholar, Web of Science, China National Knowledge Infrastructure, China Wan Fang Literature Database, and China WeiPu Literature Database.

Conflicts of Interest: The authors declare no conflict of interest.

\section{References}

1. Yan, X.; Lu, W.; An, Y. Uncertainty analysis of parameters in non-point source pollution simulation: Case study of the application of the Soil and Water Assessment Tool model to Yitong River watershed in northeast China. Water Environ. J. 2019, 33, 390-400. [CrossRef]

2. Chen, C.; Cheng, T.; Wang, Z.L.; Han, C.H. Removal of Zn2+ in aqueous solution by Linde F (K) zeolite prepared from recycled fly ash. J. Indian Chem. Soc. 2014, 91, 1-7.

3. Chen, C.; Cheng, T.; Shi, Y.S.; Tian, Y. Adsorption of Cu(II) from aqueous solution on fly ash based linde F (K) Zeolite. Iran. J. Chem. Chem. Eng. 2014, 33, 29-35.

4. Wang, Z.; Qin, H.; Liu, X. Health risk assessment of heavy metals in the soil-water-rice system around the Xiazhuang uranium mine, China. Environ. Sci. Pollut. Res. 2019, 26, 5904-5912. [CrossRef] [PubMed]

5. Chen, C.; Cheng, T.; Zhang, X.; Wu, R.; Wang, Q. Synthesis of an efficient Pb adsorption nano-crystal under strong alkali hydrothermal environment using a gemini surfactant as directing agent. J. Chem. Soc. Pak. 2019, 41, 1034-1038.

6. He, X.J.; Wang, L.; Ke, B.; Yue, Y.M.; Wang, K.L.; Cao, J.H.; Xiong, K.N. Progress on ecological conservation and restoration for China Karst. Acta Ecol. Sin. 2019, 39, 6577-6585. (In Chinese)

7. Cai, X.F.; Ge, C.X.; Wang, X.L. Advances and perspectives in research of spinach breeding technology in China. Jiangsu J. Agric. Sci. 2019, 35, 996-1005. (In Chinese)

8. Chopra, A.K.; Pathak, C. Bioaccumulation and translocation efficiency of heavy metals in vegetables grown on long-term wastewater irrigated soil near Bindal River, Dehradun. Agric. Res. 2012, 1, 157-164. [CrossRef]

9. Gao, L.; Shen, G.; Zhang, J. Accumulation and distribution of cadmium in flue-cured tobacco and its impact on rhizosphere microbial community. Pol. J. Environ. Stud. 2015, 24, 1563-1569. [CrossRef]

10. Ru, S.H.; Zhang, G.Y.; Zhang, S.Y. Study on the characteristics and regularity of enrichment of heavy metals $\mathrm{Cu}, \mathrm{Zn}, \mathrm{Pb}$ and $\mathrm{Cd}$ in vegetables. In Proceedings of the 11th National Congress of Soil Society of China and the 7th Cross Strait Symposium on Soil and fertilizer, Beijing, China, 24 September 2008.

11. Sun, S.; Li, J.M.; MA, Y.B.; Zhao, H.W. Accumulation of heavy metals in soil and vegetables of greenhouses in Hebei Province, China. J. Agric. Resour. Environ. 2019, 36, 236-244. (In Chinese)

12. Zubair, M.; Khan, Q.U.; Mirza, N.; Sarwar, R.; Khan, A.A.; Baloch, M.S.; Fahad, S.; Shah, A.N. Physiological response of spinach to toxic heavy metal stress. Environ. Sci. Pollut. Res. 2019, 26, 31667-31674. [CrossRef]

13. Yang, H.; Liu, Y.; Luo, X.; Liu, X.; Yang, S. Cause analysis for the different change profiles of sedimentary heavy metals in Qilu Lake (Yunnan-Guizhou Plateau, China) over the past century. Water Air Soil Pollut. 2020, 231, 487-493. [CrossRef]

14. Chi, N.T.L.; Anto, S.; Ahamed, T.S.; Kumar, S.S.; Shanmugam, S.; Samuel, M.S.; Mathimani, T.; Brindhadevi, K.; Pugazhendhi, A. A review on biochar production techniques and biochar based catalyst for biofuel production from algae. Fuel 2020, $287,119411$. [CrossRef]

15. Yao, N.; Chen, C.; Li, D.J.; Hu, Y.L. Cobalt nanoparticles embedded over periodic mesoporous organosilica functionalized with benzotriazolium ionic liquid for efficient and heterogeneous catalytic transformation of carbon dioxide to cyclic carbonates. $J$. Environ. Chem. Eng. 2020, 8, 103953. [CrossRef]

16. Cheng, T.; Chen, C.; Tang, R.; Han, C.H.; Tian, Y. Competitive adsorption of $\mathrm{Cu}, \mathrm{Ni}$, Pb and Cd from aqueous solution onto fyash-based Linde F(K) zeolite. J. Chem. Chem. Eng. 2018, 37, 61-72.

17. Dhiman, J.; Prasher, S.O.; Elsayed, E.; Patel, R.M.; Nzediegwu, C.; Mawof, A. Effect of hydrogel based soil amendments on heavy metal uptake by spinach grown with wastewater irrigation. J. Clean. Prod. 2021, 311, 127644. [CrossRef]

18. Malandrino, M.; Abollino, O.; Buoso, S.; Giacomino, A.; La Gioia, C.; Mentasti, E. Accumulation of heavy metals from contaminated soil to plants and evaluation of soil remediation by vermiculite. Chemosphere 2011, 82, 169-178. [CrossRef] [PubMed]

19. Tan, G.D.; He, C.L.; Wu, J.D.; Li, W.Z.; He, K.N. Effect of municipal sludge organic fertilizer on spinach growth and soil environment. J. Anhui Agri. Sci. 2011, 39, 8954-8956. (In Chinese)

20. Liu, X.; Zheng, J.; Zhang, D.; Cheng, K.; Zhou, H.; Zhang, A.; Li, L.; Joseph, S.; Smith, P.; Crowley, D.; et al. Biochar has no effect on soil respiration across Chinese agricultural soils. Sci. Total Environ. 2016, 554, 259-265. [CrossRef] 
21. Han, C.H.; Xie, W.F.; Chen, C.; Cheng, T. Evaluating the heavy metal risks of soil and rice from a farmland in a Nanjing suburb through in-vitro simulation tests. Pol. J. Environ. Stud. 2021, 30, 2093-2105. [CrossRef]

22. Gashe, M.D.; Danno, B.L. Heavy metal contents of selected commercially available oil-based house paints intended for residential use in Ethiopia. Environ. Sci. Pollut. Res. 2020, 27, 17175-17183.

23. Mandre, M.; Lukjanova, A. Biochemical and structural characteristics of Scots pine (Pinus sylvestris L.) in an alkaline environment. Est. J. Ecol. 2011, 60, 264-283. [CrossRef]

24. Wang, J.; Wang, H.; Cao, Y.; Bai, Z.; Qin, Q. Effects of soil and topographic factors on vegetation restoration in opencast coal mine dumps located in a loess area. Sci. Rep. 2016, 6, 22058. [CrossRef] [PubMed]

25. Huang, B.; Long, J.; Liao, H.; Liu, L.; Li, J.; Zhang, J.; Li, Y.; Wang, X.; Yang, R. Characteristics of bacterial community and function in paddy soil profile around antimony mine and its response to antimony and arsenic contamination. Int. J. Environ. Res. Public Health 2019, 16, 4883. [CrossRef]

26. Hakanson, L. An ecological risk index for aquatic pollution control: A sedimentological approach. Water Res. 1980, 14, 975-1001. [CrossRef]

27. Zhao, X.; Joo, J.C.; Lee, J.K.; Kim, J.Y. Mathematical estimation of heavy metal accumulations in Helianthus annuus L. with a sigmoid heavy metal uptake model. Chemosphere 2019, 220, 965-973. [CrossRef]

28. Wang, S.; Kwak, J.H.; Islam, M.S.; Naeth, M.A.; El-Din, M.G.; Chang, S.X. Biochar surface complexation and Ni(II), Cu(II), and $\mathrm{Cd}(\mathrm{II})$ adsorption in aqueous solutions depend on feedstock type. Sci. Total Environ. 2020, 712, 136538. [CrossRef]

29. Chen, X.; He, H.Z.; Chen, G.K.; Li, H.S. Effects of biochar and crop straws on the bioavailability of cadmium in contaminated soil. Sci. Rep. 2020, 10, 9528. [CrossRef]

30. Wang, Y.; Wang, L.X.; Deng, X.Y.; Gao, H.T. A facile pyrolysis synthesis of biochar/ZnO passivator: Immobilization behavior and mechanisms for $\mathrm{Cu}(\mathrm{II})$ in soil. Environ. Sci. Pollut. Res. 2020, 27, 1888-1897. [CrossRef]

31. Inyang, M.I.; Gao, B.; Yao, Y.; Xue, Y.; Zimmerman, A.; Mosa, A.; Pullammanappallil, P.; Ok, Y.S.; Cao, X. A review of biochar as a low-cost adsorbent for aqueous heavy metal removal. Crit. Rev. Environ. Sci. Technol. 2016, 46, 406-433. [CrossRef]

32. Zhou, T.; Zhou, G.D.; He, M.M. Research progress in the mechanism of biochar adsorption of heavy metals from soil. J. Hangzhou Norm. Univ. 2018, 17, 404-410. (In Chinese)

33. Lin, B.; Gao, H.; Lai, H.; Li, C.; Wang, Q. Characterization of heavy metals in soils from typical tobacco cultivated areas, China. Environ. Prog. Sustain. Energy 2016, 36, 483-488. [CrossRef]

34. Jiang, J.; $\mathrm{Xu}, \mathrm{R} . \mathrm{K}$. Application of crop straw derived biochars to $\mathrm{Cu}(\mathrm{II})$ contaminated Ultisol: Evaluating role of alkali and organic functional groups in $\mathrm{Cu}(\mathrm{II})$ immobilization. Bioresour. Technol. 2013, 133, 537-545. [CrossRef]

35. Jiang, T.Y.; Jiang, J.; Xu, R.K.; Li, Z. Adsorption of $\mathrm{Pb}(\mathrm{II})$ on variable charge soils amended with rice-straw derived biochar. Chemosphere 2012, 89, 249-256. [CrossRef] [PubMed]

36. Dong, X.L.; Guan, T.Y.; Li, G.T.; Lin, Q.; Zhao, X. Long-term effects of biochar amount on the content and composition of organic matter in soil aggregates under field conditions. J. Soils Sediments 2012, 16, 1481-1497. [CrossRef]

37. Melaku, T.; Ambaw, G.; Nigussie, A.; Woldekirstos, A.N.; Bekele, E.; Ahmed, M. Short-term application of biochar increases the amount of fertilizer required to obtain potential yield and reduces marginal agronomic efficiency in high phosphorus-fixing soils. Biochar 2020, 2, 503-511. [CrossRef]

38. Gan, W.J.; He, Y.; Zhang, X.F.; Zhang, S.; Lin, Y. Effects and mechanisms of straw biochar on remediation contaminated soil in electroplating factory. J. Ecol. Rural. Environ. 2012, 28, 83-87. (In Chinese)

39. Liu, Y.Y.; Qin, H.Z.; Li, L.Q.; Pan, G.; Zhang, X.; Zheng, J.; Han, X.; Yu, X. Adsorption of $\mathrm{Cd}^{2+}$ and Pb ${ }^{2+}$ in aqueous solution by biochars produced from the pyrolysis of different crop feedstock. Ecol. Environ. Sci. 2012, 21, 146-152. (In Chinese)

40. Rees, F.; Simonnot, M.O.; Morel, J.L. Short-term effects of biochar on soil heavy metal mobility are controlled by intra-particle diffusion and soil pH increase. Eur. J. Soil Sci. 2014, 65, 149-161. [CrossRef]

41. Sohi, S.P.; Krull, E.; Lopez-Capel, E.; Bol, R. A review of biochar and its use and function in soil. Adv. Agron. 2010, 105, 47-82.

42. Abit, S.M.; Bolster, C.H.; Cai, P.; Walker, S.L. Influence of feedstock and pyrolysis temperature of biochar amendments on transport of Escherichia coli in saturated and unsaturated soil. Environ. Sci. Technol. 2012, 4615, 8097-8105. [CrossRef] [PubMed]

43. Guo, K.Y.; Zhao, Y.Z.; Liu, Y.; Chen, J.; Wu, Q.; Ruan, Y.; Li, S.; Shi, J.; Zhao, L.; Sun, X.; et al. Pyrolysis temperature of biochar affects ecoenzymatic stoichiometry and microbial nutrient-use efficiency in a bamboo forest soil. Geoderma 2020, $363,114162$. [CrossRef]

44. Rhodes, A.H.; Carlin, A.; Semple, K.T. Impact of black carbon in the extraction and mineralization of phenanthrene in soil. Environ. Sci. Technol. 2008, 42, 740-745. [CrossRef]

45. Kharazi, A.; Leili, M.; Khazaei, M.; Alikhani, M.Y.; Shokoohi, R. Human health risk assessment of heavy metals in agricultural soil and food crops in Hamadan. Iran. J. Food. Compos. Anal. 2021, 100, 103890. [CrossRef]

46. Song, X.D.; Xue, Y.Y.; Chen, D.Z.; He, P.J.; Dai, X.H. Application of biochar from sewage sludge to plant cultivation: Influence of pyrolysis temperature and biochar-to-soil ratio on yield and heavy metal accumulation. Chemosphere 2014, 109, $213-220$. [CrossRef]

47. Zheng, R.L.; Chen, Z.; Cai, C.; Tie, B.; Liu, X.; Reid, B.J.; Huang, Q.; Lei, M.; Sun, G.; Baltrènaitè, E. Mitigating heavy metal accumulation into rice (Oryza sativa L.) using biochar amendment-a field experiment in Hunan, China. Environ. Sci. Pollut. Res. 2015, 22, 11097-11108. [CrossRef]

48. Bu, X.L.; Xue, J.H. Biochar effects on soil habitat and plant growth: A review. Ecol. Environ. 2014, 10, 535-540. (In Chinese) 
49. Liang, Y.Y.; Yi, X.J.; Dang, Z. Pollution and risk assessment of heavy metals in agricultural soils around a Pb-Zn tailing pond. J. Agro-Environ. Sci. 2019, 38, 103-110. (In Chinese)

50. Zhang, H.; Wang, H.; Tang, H.Y. Heavy melal polltion characterisics and healh risk evaluation of soil and vegetables in various hunctionalareas of lead-zinc tailings pond. Acta Sci. Circumstanliae 2020, 40, 1085-1094. (In Chinese)

51. Sawut, R.; Kasim, N.; Maihemuti, B.; Hu, L.; Abliz, A.; Abdujappar, A.; Kurban, M. Pollution characteristics and health risk assessment of heavy metals in the vegetable bases of northwest China. Sci. Total Environ. 2018, 642, 864-878. [CrossRef] [PubMed] 